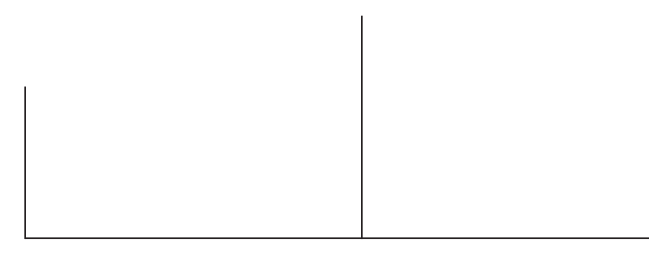

\title{
Psicanálise do sensível. A dimensão corporal da transferência*
}

\author{
Ivanise Fontes
}

\begin{abstract}
O artigo apresenta um resumo das idéias desenvolvidas pela autora em sua tese de doutorado intitulada "A memória corporal e a transferência".

O fenômeno da transferência é colocado em evidência por favorecer o retorno das impressões sensíveis, devido ao seu aspecto regressivo alucinatório. Ela é propícia ao despertar da memória corporal do paciente e isso tem fornecido novos elementos para o tratamento de pacientes somatizantes, assim como de outras estruturas psíquicas.

A autora pretende, assim, restituir ao sensorial o lugar que ele merece na teoria e técnica psicanalítica.
\end{abstract}

* O artigo resume as idéias desenvolvidas em tese de doutorado intitulada "La mémoire corporelle et le transfert", orientada pelo Prof. Dr. Pierre Fédida, defendida pela autora em outubro de 1998 no Laboratoire de Psychopathologie Fondamentale et Psychanalyse - Université Paris 7. 


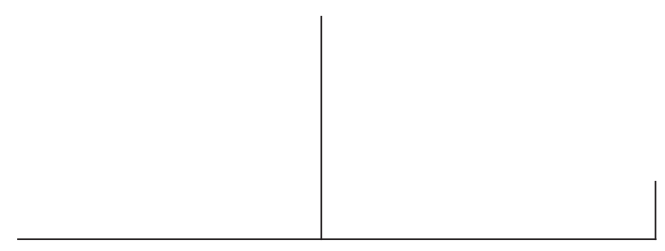

A lembrança fica impressa no corpo e é somente lá que ela pode ser despertada. ${ }^{1}$

S. Ferenczi

O interesse pelo tema do sensorial na psicanálise nasceu de uma necessidade de repensar a técnica psicanalítica. Tornou-se objeto de pesquisa de doutorado sob o título "A memória corporal e a transferência".

$\mathrm{Na}$ análise de pacientes somatizantes, as manifestações corporais são índices evidentes para uma investigação sobre os conflitos. O estudo aqui apresentado partiu inicialmente do trabalho analítico com esses pacientes e, em seguida, ampliou-se pela constatação de que podemos observar também em outras estruturas psíquicas, através do corpo, um elo associativo necessário ao desenvolvimento do tratamento. A existência de uma memória de sensações propiciou reconhecer que uma via sensorial é parte inerente à comunicação analista-analisando.

Uma hipótese foi formulada:

"As sensações que foram registradas filo e ontogeneticamente pelo indivíduo podem reaparecer na transferência com o analista quando o paciente encontra o espaço apropriado à repetição de cenas as mais precoces."

1. S. Ferenczi. "Notas e fragmentos", in Obras completas - Psicanálise 4. São Paulo, Martins Fontes, 1992, p. 268 . A tradução desta citação na referida publicação é "A lembrança fica imobilizada no corpo e é somente lá que ela pode ser despertada". A palavra coincé, da tradução francesa, aparece aqui como "imobilizada", o que foi por nós substituído por "impressa", parecendo, assim, ter sido melhor respeitado o seu sentido, que está ligado ao verbo cunhar, imprimir. 
Cada indivíduo teria marcado seu corpo diferentemente segundo as impressões (eindrücke freudiana) de sua tenra infância. Essa história pessoal é registrada inicialmente através das sensações e, somente mais tarde, incluirão a linguagem.

Freud, em "O homem Moisés e a religião monoteísta" (1934-38), retoma essas impressões precoces - anteriores à aquisição da linguagem - vividas sem que o aparelho psíquico esteja então pronto a acolhê-las. Ele afirma que essas experiências inaugurais produzem fortes impressões e são relativas ao corpo próprio ou às percepções sensoriais principalmente de ordem visual e auditiva. ${ }^{2}$

Tais experiências não podem ser rememoradas pelo discurso do paciente, nem mesmo através da associação livre, porque elas foram impressas num registro sensorial antes da possibilidade de representação.

Nesse caso, em lugar de falarmos somente de associação de idéias, poderíamos considerar também, no processo analítico, uma associação de sensações. Trata-se, na verdade, de colocar em evidência uma reatualização da sensorialidade pela transferência.

Segundo Ferenczi "nos momentos em que o psiquismo falha, o organismo começa a pensar." ${ }^{3} \mathrm{Na}$ realidade, segundo nosso ponto de vista, o corpo não começa a pensar; ele já está ali, onde a história do indivíduo se faz. O corpo é testemunha de todas as circunstâncias vividas pelo indivíduo. Ele não esquece. E mantém a memória do acontecimento.

Trata-se de uma memória que pode restituir a experiência vivida, uma memória corporal onde ficaram impressas as marcas da situação traumática. O registro foi feito no corpo e, nesse caso, ele só pode ser despertado pelo corpo.

Através do fenômeno da repetição, característica fundamental do processo de transferência, as seqüelas de impressões deixadas pelas experiências de um tempo precoce poderão retornar. Esse material, muito vivo, muito "carnal", retornará evidentemente em busca de ser representado. A transferência se presta a essa reprodução de sensações anteriormente experimentadas. É algo que se manifesta bruscamente, através do aparelho visual, auditivo etc., como uma alucinação; a transferência oferecendo as condições de um retorno do material inconsciente não somente recalcado, mas registrado em uma outra ordem - a ordem do sensorial. Dessa forma, a transferência fornece a possibilidade de repetição, mas o que se repete são farrapos de impressões de infância, fragmentos de lugares, de rostos, de sons e odores.

2. S. Freud. "O homem Moisés e a religião monoteísta" (1939). E.S.B., vol. XXIII. Rio de Janeiro, Imago, 1975, p. 93.

3. S. Ferenczi. Diário clínico (1932). São Paulo, Martins Fontes, 1990, p. 37. 


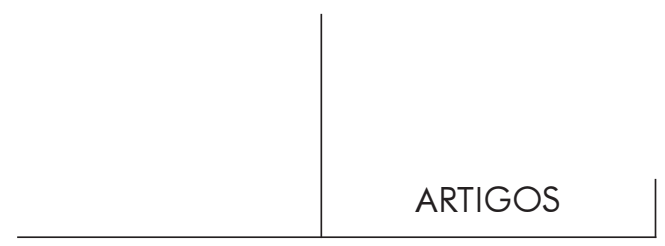

É preciso admitir que o analista e o analisando, provocados por esses "efeitos especiais" de uma memória corporal assim despertada, vivem o que poderíamos chamar de "a inquietante estranheza da transferência".

É uma manifestação corporal inesperada que adentra o espaço analítico e que indica uma experiência já vivida; irrupção similar ao advento de um ato falho, dessa vez no campo perceptivo.

Ferenczi considerava a interpretação dos sonhos como uma via possível e importante de acesso às impressões sensíveis. Este trabalho reflete uma outra possibilidade: a de observar um retorno dessas impressões através de uma memória corporal que reaparece pela transferência.

J.-B. Pontalis, em seu texto "A estranheza da transferência", considera que é como se viesse um tempo - um tempo necessário - onde nós não pudéssemos mais nos satisfazer com palavras e evocações, com cadeias associativas, com ligações e desligações, com deslocamentos e condensações. "Nós exigimos a 'libra da carne'. Nós exigimos ser pagos em natureza e em pessoa, sem moeda de troca." ${ }^{\circ} \mathrm{E}$ talvez seja por isso que, segundo ele, a transferência não se relata, nem se escreve nem se traduz, ela não é um texto: daí a insuficiência básica de toda descrição de análise. “... a transferência escapa à ordem e a violência do discurso" 6 .

Em seu texto de $1938^{7}$ Freud dizia que não nos surpreendemos o bastante com o fenômeno da transferência. "É uma coisa bem estranha que o analisando reencarne no seu analista um personagem do passado."

Estamos diante da evidência de uma reencarnação pela transferência. Não se trata de um elemento de ordem espiritual, ao contrário, o sentido é muito próximo de sua etimologia: carne. Reencarnar significa se fazer carne de novo. Do latim incarnare, seu sentido literário: representar (uma coisa abstrata) sob uma forma material e sensível - um corpo carnal. Fato é que na transferência uma reencarnação tem lugar com toda a conotação de "tornar-se carne".

Nesse sentido é importante retornar ao que Ferenczi chamava "transe" para nomear esses momentos onde o par analítico se encontra de maneira particular. O analista deveria buscar "colocar-se no mesmo diapasão do doente, sentir com ele todos os seus caprichos, humores,..." como propunha em seu texto "Elasticidade da técnica psicanalítica" . A partir dessa condição é que o analista

4. J.-B. Pontalis. La force d'attraction. Paris, Seuil,1990.

5. Idem, p. 70 .

6. Idem, p. 73

7. S. Freud. Abregé de psychanalyse (1938), trad. fr. Paris, P.U.F.

8. Idem, p. 42

9. S. Ferenczi. "Elasticidade da técnica psicanalítica", in Escritos psicanalíticos (1909-1933). Rio de Janeiro, Taurus, 1988. 


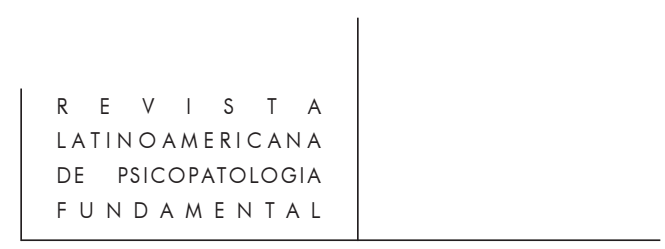

poderá ser capaz de suportar e metabolizar as expressões íntimas que constituem o "inédito que há na transferência" ${ }^{10}$, segundo a formulação de $\mathrm{M}$. Torok.

Do ponto de vista desta autora uma demanda indireta é endereçada a o analista: o papel de "médium" para acolher as catástrofes ligadas ao trauma. A arte desse "analista-médium" seria saber convocar, chamar, ressuscitar por todos os meios que sua imaginação lhe fornece esses momentos traumáticos.

Nessa perspectiva, cabe aqui colocar em evidência uma noção que ocupa lugar de importância na investigação: o aspecto regressivo alucinatório da transferência.

A idéia de uma tendência à regressão em ação na vida psíquica como na vida orgânica era defendida por S. Ferenczi. E é esse fenômeno que pode expressar, na transferência, o movimento de retorno ao infantil e também ao passado imemorial da espécie.

Freud, em "Construções em análise" (1937), se refere à presença ocasional de verdadeiras alucinações surgidas no curso de uma análise, certamente não psicóticas:

Talvez seja um caráter mais geral da alucinação, que justamente até o presente não foi suficientemente posto em valor, que nela retorna alguma coisa de vivido e depois esquecido dos tempos precoces, alguma coisa que a criança viu ou ouviu numa época onde ela mal sabia falar, e que se impõe agora à consciência, verdadeiramente deformado e deslocado sob o efeito das forças que se opõem a um tal retorno. ${ }^{11}$

A circunstância da transferência favorece extraordinariamente a instauração de manifestações as mais refinadas. É essa a razão pela qual o analista e o analisando serão colocados numa situação em que os movimentos regressivos poderão ter lugar, aspectos corporais incluídos.

Quando uma relação analítica atinge níveis mais arcaicos, as palavras não são possíveis e são as sensações que têm lugar. É preciso, então, que o analista seja capaz de colocar em ação sua imaginação, sua capacidade de regressão, para poder ter acesso a esse material fornecido pelo paciente em estado de transferência (ou em estado de transe....).

É graças a esse poder de imaginação analógica e metafórica do analista que, segundo Fedida, o paciente pode usufruir terapeuticamente de sua regressão no

10. M. Torok, A. Covello et R. Gentis. "Entretien autour de Sandor Ferenczi", in Bloc-notes de Psychanalyse, $\mathrm{n}^{\mathrm{0}}$ 2, 1982, pp. 46-47.

11. S. Freud. "Construções em análise" (1937). E.S.B. Rio de Janeiro, Imago, 1975, p. 302. 


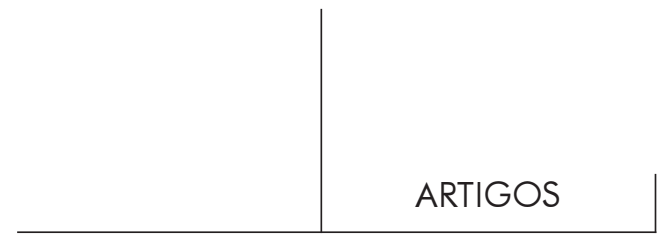

tratamento. ${ }^{12}$ "Trata-se de reconhecer a verdadeira função restauradora da regressão." 13

E, nessa medida, o fenômeno da transferência ganha uma dimensão surpreendente.

\section{Em direção às palavras: do sensorial à linguagem}

O ponto de vista acima exposto tem como fundamento a concepção de que o psíquico se desenvolve em constante referência à experiência corporal. Segundo Anzieu, depois de decênios de dominação intelectual do estruturalismo e da lingüística, o retorno da psicanálise às realidades corporais fundadoras torna-se essencial. ${ }^{14}$ Ele mostra que Freud foi o precursor da noção de Eu-pele ao considerar que o Ego deriva, em última instância, das sensações corporais, principalmente daquelas que têm sua origem na superfície do corpo - é a projeção mental da superfície do corpo. ${ }^{15}$

É nesse sentido que não podemos dizer que há despertar do sujeito enquanto uma significância das percepções e das sensações não tiver lugar.

Doentes deste fim de século, apresentando as "novas doenças da alma"16 (como costuma se referir Kristeva), mostram uma dificuldade crescente de ligar corpo à palavra. Esses pacientes, que nos impõem impasses técnicos, exigem do analista uma intervenção em que as palavras encontrem maior capacidade sensorial.

Quando a linguagem ignora de quem ela é herdeira, sua origem sensorial, surgem discursos vazios. Esse elo que falta é que adoece o sujeito. É então necessário o trabalho de restituir a vitalidade da linguagem. Dessa forma, a via analítica tem mão dupla: nomear as sensações e, por outro lado, dar corpo à linguagem.

Sair de uma psicanálise onde reina a abstração seria revitalizá-la. Segundo Green, podemos afirmar que a análise pára de ser um trabalho sobre as representações e se torna, em alguns casos, um trabalho da representação. ${ }^{17}$

12. P. Fédida. "La régression, formes et déformations", in Revue Internationale de Psychopathologie. Paris, P.U.F., 1994.

13. Idem, p. 46.

14. D. Anzieu. L'épiderme nomade et la peau psychique. Paris, Apsygée, 1990, p. 48.

15. S. Freud. "O ego e o id" (1923). E.S.B., vol. XIX. Rio de Janeiro, Imago, 1976, p. 40.

16. J. Kristeva. Les nouvelles maladies de l'âme. Paris, Fayard, 1993.

17. A. Green. "La représentation de chose entre pulsion et langage", in Psychanalyse à l'Université. Paris, juillet 1987, p. 366. 
São vários os autores contemporâneos que, como Green, formulam elaborações teóricas sobre a importância do sensorial, do perceptivo e de sua relação com o representacional no trabalho do analista. A psicanálise francesa, através de P. Fédida, J. Kristeva, D. Anzieu e J. McDougall, tem se voltado para essa problemática.

Esta pesquisa sobre um memória corporal despertada pela transferência tem a intenção de ser uma contribuição a mais, visando restabelecer o lugar do sensorial na teoria e técnica psicanalíticas.

\section{Resumos}

El artículo presenta un resumen de las ideas desarrolladas por la autora en su tesis de doctorado: "La memoria corporal y la transferencia".

El fenómeno de transferencia es puesto en evidencia para favorecer el retorno de las impresiones sensibles debido a su aspecto regresivo alucinatorio. Este fenómeno facilita el despertar de la memoria corporal del paciente y esto nos ha proporcionado nuevos elementos para el tratamiento de los pacientes somatizantes, así como de otras estructuras psíquicas.

La autora pretende así restituir lo sensorial al lugar que merece en la teoría y la técnica psicoanalítica.

L'article présente un résumé des idées développées par l'auteur dans sa thèse de doctorat intitulée "La mémoire corporelle et le transfert".

Le phénomène du transfert est mis en évidence pour favoriser le retour des impressions sensibles, à cause de son aspect régressif hallucinatoire. Il est propice au réveil de la mémoire corporelle du patient et cela nous a fourni des nouveaux éléments pour la cure des patients somatisants, ainsi que d'autres structures psychiques.

L'auteur envisage, ainsi, de redonner au sensoriel la place qu'il mérite dans la théorie e la tecnique psychanalytique.

This article summarizes the basic ideas presented by the author in her doctoral thesis: "The bodily memory and the transfer".

The transfer phenomenon gains a special place because it favors the retrieval of sensible impressions through its hallucinatory regressive characteristic. The transfer is used to allow the emergence of the patient's bodily memory, this process has given us new elements to treat somatic patients and also patients with other psychic structures.

The author also intends to emphasize the role of the sensorial in the psychoanalytic theory and technique. 